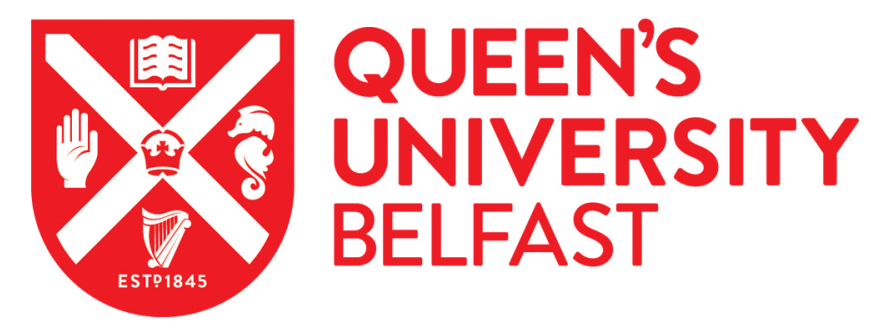

\title{
Delivering Social Work Education on Case Reviews and Inquiry Reports: An Exploratory Study of Students' Perspectives in Northern Ireland
}

Houston, S., \& McColgan, M. (2014). Delivering Social Work Education on Case Reviews and Inquiry Reports: An Exploratory Study of Students' Perspectives in Northern Ireland. Child Care in Practice, 20(4), 415-435. https://doi.org/10.1080/13575279.2014.936363

Published in:

Child Care in Practice

Document Version:

Peer reviewed version

Queen's University Belfast - Research Portal:

Link to publication record in Queen's University Belfast Research Portal

Publisher rights

( 2014 The Child Care in Practice Group. This is an Accepted Manuscript of an article published by Taylor \& Francis in Child Care in Practice in 2014, available online: http://wwww.tandfonline.com/10.1080/13575279.2014.936363.

\section{General rights}

Copyright for the publications made accessible via the Queen's University Belfast Research Portal is retained by the author(s) and / or other copyright owners and it is a condition of accessing these publications that users recognise and abide by the legal requirements associated with these rights.

Take down policy

The Research Portal is Queen's institutional repository that provides access to Queen's research output. Every effort has been made to ensure that content in the Research Portal does not infringe any person's rights, or applicable UK laws. If you discover content in the Research Portal that you believe breaches copyright or violates any law, please contact openaccess@qub.ac.uk. 


\section{Delivering Social Work Education on Case Reviews and Inquiry Reports: An Exploratory Study of Students' Perspectives in Northern Ireland}

It is self-evident that we live in the age of the inquiry where the negative impact of risk has been examined through numerous formal processes. In the wake of such scrutiny, there have been repeated recommendations for better training of the professionals charged with safeguarding the welfare of vulnerable individuals. Yet, there has been very little examination of how student social workers, in particular, evaluate this training. This exploratory study responded to this gap through a mixed-methods design centring on the views of qualifying and post-qualifying social work students attending courses within two regional universities in Northern Ireland. The study found that, in the main, the cohorts responded favourably to certain aspects of the curriculum and how they were delivered. That said, the emotive nature of the case review and inquiry reports was inadequately addressed in the classroom nor processed afterwards through a psycho-social framework. In effect, students were often left with residual anxieties that potentially hampered learning. On the basis of the findings, the study calls for further research into this highly significant area of professional competence.

Key words: social work education, inquiry, evaluation, case review

\section{Introduction}

It is self-evident that we live in the risk society (Beck, 1992) where uncertainty looms large in everyday life. Whether the focus centres on threats of terrorist attack, the collapse of global markets or ecological disaster, risk assessment infiltrates public and private discourse. Not only that, moral panics about risk have become far-reaching, as has a societal preoccupation with dangerousness. In the wake of these trends there is a notable lack of confidence in public bodies to obviate or at least ameliorate the worst outcomes of uncertainty. Moreover, social care organizations unleash new forms of surveillance on staff and protective services as part of their commitment to corporate governance (Wrennall, 2010). 
Nowhere have these emergent trends been seen so clearly as in the world of human vulnerability. Whether it is children exposed to acts of cruelty at the hands of their caregivers, or vulnerable adults succumbing to acts of exploitation, human welfare services grapple constantly with risk assessment and management. This takes on a particular purchase when vulnerability leads to the death of, or very serious, irredeemable harm to, susceptible individuals. Public bodies in Anglophile countries respond typically to these events through a quasi-forensic mode of inquiry looking at what went wrong and seeking to 'learn the lessons' so that future practices will be safer.

In child welfare, a number of inquiries have tried to understand why supposedly obvious signs and symptoms in children were not recognised by professionals trained in safeguarding procedures. Similarly, case reviews have sought to examine professional responses to serious harms inflicted on vulnerable adults (MacKay, 2004; Social Care Institute for Excellence, 2009). In many cases in the UK, the interface between parental mental health and risks to children has been investigated (for example, see Western \& Eastern Health \& Social Services Boards, 2008); or the focus has concentrated on institutonal harm (Hughes, 1986) or forms of organised abuse (Clyde, 1992). Some reviews have centred on acts of professional omission (Haringey Safeguarding Board, 2009) while other inquiries have examined deeds of commission (Butler-Sloss, 1988).

The considerable range of inquiries and case reviews have been analysed (Reder \& Duncan, 2004; Stanley \& Manthorpe, 2004; Cooper, 2005), metaanalysed (Brandon et al, 2010; Manthorpe \& Martineau, 2011; Devaney et al, 2013) and reviewed theoretically (Reder et al, 1993; Rustin, 2005) in an attempt to distil core messages for professionals and discover underpinning themes. These included, chiefly, psychological blocks to recognition, poor communication and interagency engagement, the presence of internal factors in carers such as stress, and external factors in the wider environment including social isolation and poverty.

Such findings must, however, be critically appraised. When it came to child protection, for instance, Munro (2011) argued that serious case reviews had concentrated on the identification of professional error rather than looking 
more deeply for underpinning, inter-connected causes. This had led to a blame culture and escalation of the 'fear factor' amongst professionals. She recommended that review panels adopt a systems approach to counter this tendency. Within this process, wider organizational factors are examined particularly in terms of the constraints they impose on professional practice.

Significantly for this study, many case reviews and inquiry reports incorporated a section outlining recommendations for education and training. For example, the Climbie Inquiry Report recommended that, 'the training of social workers must equip them with the confidence to question the opinion of professionals in other agencies when conducting their own assessment of the needs of a child' (House of Commons, paragraph 5, 2003, p.138). In a different vein, the Cleveland Report called for interagency training focusing, amongst other things, on the roles of different professionals in the assessment of child sexual abuse (Butler-Sloss, 1988, pgs. 251-252).

Ferguson (2005) built on these recommendations by arguing that social work education must have, at its core, a theoretical perspective in order to understand the psychological aspects of child protection work. Drawing on the Victoria Climbié case, he appraised the complex dynamics arising from resistance, projection, defended behaviour, transference and countertransference. Similarly, Rustin (2005) examined the Climbie case from a psycho-analytical angle, noting that social workers needed to be trained to be mindful of their emotional reactions to traumatic events in children's lives. Reder and Duncan (2004) concurred arguing that critical thinking skills must be enhanced rather than relying only on over-bureaucratised responses to riskladen situations.

In summary, even though the afore-mentioned recommendations have been strident in their call for change, research into social work education is only beginning to establish rudimentary themes. More specifically, we need to know how students make sense of the learning strategies adopted by educational institutions and whether and how such strategies lead to better outcomes for service users (Carpenter, 2011). This gap in our understanding becomes magnified when it comes to the emotionally charged areas of the case review and inquiry report - and how they are taught within the social 
work curriculum. With so many resources being invested in educational programmes, it is imperative we enhance our understanding of the students' persepctives given they are the recipients of these highly specialised attempts at knowledge transfer.

Method

In Northern Ireland, social work education (at degree level) is delivered primarily by two universities: Queen's University Belfast (QUB) and the University of Ulster (UU). At the post-qualifying level, the two universities are also major providers, along with agency partners, of master's level programmes. The aim of this exploratory study was to appraise how these universities disseminated knowledge from the inquiry reports and case reviews to social work students, and how the latter evaluated this educational input.

At this point, we need to briefly explain the difference between a 'review' and an 'inquiry' within the UK context. With regard to the former process, an independent committee is usually convened. Its task is to examine the factors leading to the death of, or serious harm to, a vulnerable person, consider the important lessons to be apprehended from the case, and make recommendations about future practice. Such reviews are likely to take place under the aegis of legislative and policy instruments. Moreover, the terms of reference are drawn up invariably by a statutory agency or body and the findings reported back to it.

In England and Wales, the term 'serious case review' is given to this process; in Scotland it is labelled a 'significant case review'; and in Northern Ireland it is referred to as a 'case management review'. All three are broadly similar in structure. As a matter of convenience, we adopt the umbrella term, 'case review', in this paper to represent this typology. An inquiry, by way of contrast, is normally convened by government under legislation, in lieu of the death of, or serious harm to, a vulnerable person where there is great public concern and media interest about the management of the case. The terms of reference are established by a government minister and the findings reported back to him or her. 
Using these definitions, the study also sought to compare the perspectives of different types of student: qualifying, newly qualified and post-qualified. A comparison of this kind was important to know as these groups were at different stages of professional development. Thus, the post-qualified group had ostensibly more experience in the field with which to integrate and make sense of imparted knowledge whereas the qualifying group (most likely) came to the area with less awareness of the presenting issues. That said, they brought a 'fresh eye' to received wisdom about the subject-area.

In relation to the qualifying level of training, both universities offered a broadly similar social work curriculum for undergraduate students reflecting their role as partners in the region's 'Social Work Degree Partnership' (a consortium of higher education and agency stakeholders). Hence, findings from the inquiry reports were mainstreamed throughout the curriculum and were also chiefly addressed in area-specific modules covering child-care and mental health social work. By way of contrast, the three post-qualifying programmes (dealing centrally with safeguarding practices) were more diverse in their focus. They were constituted as: (i) a master's level, child care pathway (delivered by QUB) (ii) a master's level, mental health pathway (delivered by QUB) and (iii) a master's module in initial professional development (offered by the UU).

The study, which had previously received ethical approval from both universities' ethics committees, encompassed quantitative and qualitative methods of data collection in three, sequential phases of inquiry. The findings emanating from the first and second phases are covered in this submission.

Phase One

In the first phase, the sample comprised all the full-time, final year undergraduate social work students $(n=220)$ attending both universities. This was a total sample. These students, invariably female (93\%), were given a selfcompletion questionnaire towards the end of semester two of their university study. They consisted of students on a three year route and others (with relevant degrees) on a two year, fast-track pathway. In both programmes students were expected to pass two placements, one of 85 days, the other 100 days, and attend a number of college blocks where a generic curriculum was 
taught along with more specialist modules on different thematic areas and client-groups.

The questionnaire was also disseminated to all of the part-time students in both universities ( $n=65$ ) who attended one of the post-qualifying programmes referred to above. $57 \%$ of the sample was employed in children's services, $33 \%$ in adult services and the remaining $10 \%$ in other types of social work including criminal justice. All of the post-qualifying students were qualified for at least two years and $95 \%$ worked in the statutory sector (the remainder working in a voluntary organisation). These students were responsible for enacting the law, policy and procedure to protect either vulnerable children or adults as part of their day-to-day work. The mental health social workers also took part in conjoint assesments (with approved medical staff) to compulsorily detain adults whose mental health status placed them at risk to themselves or others. In a similar vein, the child-care social workers enacted legislation to protect children when a threshold of significant harm had been met and this could sometimes result in the child being removed into care because of serious concerns.

A questionnaire was chosen because the numbers in the sample were relatively high, it was quick to administer and easy to complete. Moreover, the researchers wanted to gain a broad, overview of the area before initiating a more in-depth, qualitative inquiry in the second phase of the study (see below). The questionnaire covered areas such as: (a) the relevance of the teaching to learning needs (b) knowledge of the reports (c) the range of teaching methods employed by the programmes (d) the quality of the teaching (e) the impact of teaching on practice and ( $f$ ) how teaching could be improved. It had been previously piloted with a small number of former students (chosen purposively) in order to promote content validity and coherence. The questions embraced a number of formats including closed questions with vertical response formats, questions adopting a likert scale and open questions inviting written comments. 172 questionnaires were returned (78\% of the total sample) from the undergraduate population compared to 42 returns from the postgraduate students (65\%). The data was analysed through 'Questback': a software programme designed for handling survey findings. 


\section{Phase Two}

There was a time interval of around four months between data collection in phases one and two. In the latter phase, follow-up, telephone interviews were carried out with a number of students who had participated in phase one: 12 newly qualified social workers (who had just left the universities) and 12 experienced social workers who were previously (or still) enrolled on the identified postgraduate courses. This sample was selected randomly from a total population of students ( $n=96$ ) indicating their willingness, at end of the questionnaire, to enage in a telephone interview. It covered the following areas: (a) the relevance of the reports to everyday practice (b) the application of specific learning on the inquiries to the development of communication skills, risk assessment and decision making (c) the discussion of reports within supervision and (d) how learning about the reports impacted on safeguarding practices.

The results were transcribed manually from notes and analysed using Miles and Huberman's (1994) three concurrent streams of data-analysis, namely: (a) data reduction (editing, segementing and summarising the data) (b) data display (organising, compressing and assembling the data), and (c) drawing and verifying conclusions (checking and supporting the meaning and implications attached to the data).

\section{Phase Three}

This third phase involved a series of in-depth interviews with programme coordinators of the afore-mentioned modules and pathways. It sought to examine their perspectives on how the reports were integrated within curriculum design and delivery. The interview schedule for these interviews was influenced by some of the salient findings arising from the preceding phases of inquiry. For instance, the researchers were keen to explore how the 'fear factor' amongst students was managed by the coordinators (see Results section below). In addition, the researchers explored the coordinator's view of involving service users in the design and delivery of the programme as phases one and two had only briefly addressed this important area. This phase also enabled the researchers to check some of the factual 
responses made by the students in the questionnaire; for example, in relation to the diversity of teaching methods that had been employed. This phase will be addressed in a different submission.

\section{Results}

Phase One

The results from phase one are presented below and organised according to a primary cross-tabulation comparing the responses of the qualifying and postqualifying groups.

\section{Coverage of Relevant Reports}

Table 1 reports on responses to the question: 'Did the programme cover the findings of the reports most relevant to your learning needs'?

\section{PLACE TABLE 1 HERE}

As can be seen a significantly higher proportion of postgraduate students (76\%) answered 'yes' to this question compared with the undergraduate cohort (54\%). The 'partly' response also showed a marked variation. Thus, $12 \%$ of the postgraduates ticked this response compared to $41 \%$ of the undergraduates.

\section{Naming the Reports}

A second question was constructed as follows: 'Can you recall any of the titles of the reports covered by the programme?'

There was more consistency in the responses here compared to the first question. Thus, $93 \%$ of undergraduates said 'yes' to the question compared to $88 \%$ of the postgraduate group. Significantly, in few instances was the exact title provided; more often than not, respondents referred to the name of the index child or family. When asked to name these reports, there was a more varied response between the groups. All in all, the undergraduates listed 28 showing a balance between adult and child reports and enumerated several relating to residential care including the Hughes Report (1986) 
(referring to the Kincora experience). Moreover, the students listed both recent and also more historical investigations going back $\mathbf{3 0}$ years or more.

For the undergraduates, the five most frequently cited reports all emanated from inquiries. Starting with most frequent and ending with the least, they were listed as: 'Climbié' (House of Commons, 2003); 'O'Neill' (WHSSB/EHSSB, 2008); 'Baby Peter' (Haringey, 2009); 'Colwell' (Committee of Inquiry, 1974); and 'Beckford' (London Borough of Brent, 1985). The national inquiry looking at the deaths of Jessica Chambers and Holly Wells (House of Commons, 2004) was mentioned along with that into the death of Stephen Lawrence (Home Office, 1999). In addition, six case review reports were listed. The most frequently cited of these was the 'Harron' report (Criminal Justice Inspection, 2006). The students also referred to inquiries where social workers had failed to prevent abuse occuring [for example, the 'Kimberley Carlisle' Inquiry Report (London Borough of Greenwich, 1987)] and inquiries where social workers were perceived to be over-zealous in identifying abuse [for instance, the 'Cleveland' Inquiry (Butler-Sloss, 1988)].

By way of contrast, the postgraduate students cited 18 reports in response to the question. There was some overlap with the undergraduate group when it came to the top five most frequently listed. These were (in order of most to least frequent): 'Climbié' (House of Commons, 2003), 'McElhill' (DHSSPS, 2008), 'O'Neill' (WHSSB/EHSSB, 2008), 'Baby Peter' (Haringey, 2009), and 'Colwell' (Committee of Inquiry, 1974). Three of the reports identified were the subject of case reviews - the most common of which was the 'Harron' report (Criminal Justice Inspection, 2006).

\section{Number and Type of Teaching Methods}

Table 2 reports on student responses to the question: 'How many of the following teaching methods (lecture, case study, discussion, service user input, interactive exercise, handout) were utilised to deliver the session(s) on the reports?'

The undergraduates responded differently to this question (due, ostensibly, to variations in recall). Of interest was the finding that a majority of the responses showed each method (alluded to) had only been appropriated on one 
occasion. Thus, just over $80 \%$ indicated that one lecture had been delivered on the theme of the inquiries; likewise, $78 \%$ said one case study, $77 \%$ said a single discussion, $81 \%$ said one session from a service user and just under $75 \%$ said they had engaged in a single, interactive exercise.

However, a range of other teaching methods were listed by the undergraduates. These included tutorials, recommended reading, videos from $\mathrm{SCIE}$, court reports and independent research. In addition, several written responses indicated the following observations:

'Unsure, mostly whistle stop through these inquiries, little covered; for example, local inquiries, no recollection if adult reviews were covered'.

'There was rarely a focus on the reports - they were more woven into lectures/discussions'.

'On-line discussion forums that posed a question/scenario that made you consider your understanding of same and avail of other students' greater experience and enables discussion re. same'.

Like the undergraduate group, a significant proportion of the postgraduate respondents indicated that only one of the listed methods had been utilised. For example, $90 \%$ said just one lecture had been presented with $97 \%$ identifying only one case study. Moreover, and unlike the undergraduate cohort, they indicated that on-line resources formed part of the suite of methods adopted.

\section{Quality of Teaching}

Respondents were asked: 'Overall, what do you think of the quality of the teaching on the reports?'

Table 3 outlines responses to this question. For $60 \%$ of the undergraduates, the programme's teaching was rated as either very good or good. This compared with $63 \%$ of the postgraduates making this response.

\section{PLACE TABLE 3 HERE}


Both cohorts were then asked to provide written comments on the quality of teaching. For the undergraduates, some of the positives were listed as follows:

'The teaching was interactive... much better in relation to family and child care'.

Very informative. Explored cases well, what went wrong and how social work skills such as communication, report writing (accurate) and sharing of info. among mulit-disciplinary professionals could be better and perhaps changed the outcome!'

'Excellent in particular remember lecture by ' $X$ ', including photographic evidence of child abuse (re. Victoria Climbie), discussion about noting evidence in hindsight...In particular ' $X$ 's advice to 'believe the unbelievable'.

However, there were also some negative reactions:

'Adult services was neglected...too much emphasis on families and children'.

'More focus needed on what could have been done differently'.

'I believe the teaching at times was detrimental to morale...It discussed the gaps within services although did not focus on better practice. I believe it should have been more focused on prevention not worst outomes'.

The postgraduates echoed some of the afore-mentioned responses:

'I felt that the teaching on the lessons from the inquiry reports provoked anxiety rather than anything else'.

'lecturer ensured information was of high quality and interaction made messages easy to remember'.

Table 4 reports on responses to the question: 'Did the programme use any helpful methods for conveying knowledge on the reports?'

\section{PLACE TABLE 4 HERE}

Around 1 in 5 respondents, from both cohorts, indicated the methods employed by programmes were unhelpful overall in transmitting essential knowledge ( $21 \%$ of the undergraduates and $22 \%$ of the postgraduates). $41 \%$ of 
the undergraduates felt more positively about the methods compared to $56 \%$ of the postgraduates. Those indicating a 'helpful' response were further asked to describe these methods. Some of them wrote:

'Programme encouraged reading the summary reports particularly Laming'

'Service user input'

'Small group discussion'

'Exams: had to learn about it'

'One lecturer got each class member to study an inquiry and feedback to the rest of the class. Interesting and informative lecturer (was a stand in lecturer)'

Some of the postgraduate students listed the following approaches:

'Useful handouts'

'Online resources'

'Access to actual reports'

'Research for assignment'

A number of undegraduates also listed methods of knowledge transmission which they viewed as discernably unhelpful:

'information on powerpoint, sometimes too boring'

'asked to read full inquiry but not discussed in tutorial'

'class discussion was frustrating when tutor and student 'stories' detracted from learning'

Two unhelpful areas were highlighted by the postgraduate group:

'powerpoint not interactive - felt lectured to'

'fear around at coffee time - people talking about what they now have to do' 


\section{Impact of Teaching on Practice}

Both groups were asked whether they agreed with 6 different statements. The first was formulated as follows: 'The teaching enhanced my decision-making skills'. Table 5 indicates that $76 \%$ of undergraduates and $71 \%$ of postgraduates either strongly agreed or agreed with the statement. Around $9 \%$ of undergraduates, and just under $10 \%$ of postgraduates, either disagreed or strongly disagreed. $15 \%$ and around $20 \%$, respectively, were uncertain.

\section{PLACE TABLE 5 HERE}

Table 5 also sets out responses to the statement: 'The teaching enhanced my skills of critical thinking'. $77 \%$ of the undergraduates and $85 \%$ of the postgraduates either agreed or strongly agreed with the statement while $16 \%$ of the former group and $10 \%$ of the latter group were uncertain.

A third statement was constituted thus: 'The teaching enhanced my skills of communication'. Only $11 \%$ of the undergraduates and $12 \%$ of the postgraduates either disagreed or strongly disagreed with the statement. 54\% of the first group and $56 \%$ of the second agreed with the statement.

The cohort was then asked to respond to a fourth statement: 'The teaching enhanced my skills of risk assessment'. $80 \%$ of the undergraduates and $76 \%$ of the postgraduates agreed or strongly agreed with the statement. $16 \%$ and $20 \%$ were uncertain, respectively.

This was followed by: 'The teaching was relevant to my day-to-day practice'. As can be seen, there was strong support for the notion that the teaching had been relevant to the daily demands of practice with $86 \%$ of undergraduates and $83 \%$ of postgraduates either strongly agreeing or agreeing.

The last statement asked the participants to judge whether the teaching had 'enhanced safeguarding interventions with vulnerable service users'. Just over one in ten undergraduates were uncertain about this as was $13 \%$ of the postgraduate cohort. 


\section{Improving Teaching and Learning}

The final part of the questionnaire asked for written responses to the question: 'have you any other comments as to how the programme's dissemination of knowledge on the reports could be improved?' Some of the responses from the undergraduates included the following:

'much more needed on Northern Ireland cases'.

'I feel the teaching was geared towards working in family and child care...there are many other areas which did not receive as much prominence...physical and learning disability, older people, alcohol and substance abuse, mental health'.

'it would have been interesting to have a real case with current social workers to answer questions. This would have given a clearer view of communication between allied profesionals and service users'.

'perhaps an essay to compare inquiry reports of the past with more recent reports to question how social work has improved/lessons learnt/ how practice has evolved...'

Some of the postgraduate students wrote:

'like all training...information can be lost or forgotten when practitioners return to practice. Refresher courses...would be beneficial'.

'it is also important for the university to liaise with the Trust and consider joint training...maybe helpful for students to research the topic of CMRs (case management reviews) prior to attending training.'

'I really do feel that adult services should be examined beyond McLernon as there are many cases of abuse'.

\section{Phase Two}

To reiterate, in phase two of the study one of the researchers instigated follow-up telephone interviews with a number of students who had participated in the first phase. This occurred approximately four months after the first round of data collection. The sample involved twelve newly qualified social workers (who had just left the universities) and twelve experienced social workers who were previously (or still) enrolled on a post-qualifying 
course. Figure 1 sets out a schematic overview of the themes arising from the telephone interviews. Two general themes (applying to both groups) arose, namely: (a) the development of professional practice and (b) impact of learning.

\section{PLACE FIGURE 1 HERE}

There were two specific themes deriving from the first general theme, namely: (i) developing holistic practice through better communication and (ii) developing risk assessment and decision-making. In relation to the first of these, the messages from the reports appeared (in most cases) to resonate strongly with current practice across a majority of service user groups, even though four post-qualifying respondents felt the reports had no relevance for their settings.

Although there was an emphasis on adhering to the procedural aspects of practice, several respondents suggested the learning promoted their capacity to take a more holistic perspective of family functioning through better multidisciplinary communication. As one newly qualified respondent said:

'What is important is the whole interagency communication and multidisciplinary working; it's important to complete the jigsaw through this'.

Others said:

'There is a lack of understanding and appreciation of how structures influence approaches'.

'The learning encourages me to do more in-depth thinking before making decisions'.

Moreover, the newly qualified group emphasised how the reports had developed their communication skills. In adopting a holistic approach with families, these respondents indicated they would spend time building up a picture of family functioning, using genograms to establish family history and communicating more openly about concerns. Thus, for one respondent her focus lay in: 
'looking out for child protection concerns; for example, if a child says something, believe... advocate for them'.

For another respondent, it was a matter of:

'communicating information to get different perspectives'.

A more complex picture emerged in relation to the development of risk assessment. Some newly qualified social workers were just grappling with the concept:

II did not know how to do a risk assessment. I had two PLOs (Practice

Learning Opportunities) but when I came out of university I didn't know how to do a UNOCINI' (a needs and risk-led agency form).

Other respondents within this group used findings from the reports to amplify their understanding of this area - leading to a much greater sense of confidence. In this regard, references were made to appraising and working with family strengths in risk assessment, building up credible, safety plans and considering how agency interventions influenced children's lives. Additionally, for some, risk assessments became more evidence-based and linked with recognised risk factors:

'my risk assessment would be more evidenced based than previously'.

For these staff, the credibilty, or trustworthiness of information, was now much more to the fore:

'I can trace exactly where I got my information and what the recommendations are; for example, observation or assessment of other professionals'.

The staff on post-qualifying courses, alternatively, were more likely to reference their use of critical reflection and conceptual frameworks to guide risk assessment:

'I use a combination of analysis, awareness of assessment tools and models. In risk of significant harm, I am working out comprehensive information'. 
That said, much like the newly qualified group, they emphasised how learning from their courses had fostered more of an holistic approach to risk assessment:

'It is about re-checking and verifying information, getting a holistic picture of the family, getting an accurate picture of risk, looking at signs from others' perspectives'.

'I now take a different angle... I use a fresh approach to critically analyse behaviour'.

Both newly qualified and more experienced staff alluded to decision-making as an area that had developed through education and training. For the former group, competence in using this skill was linked to practice opportunities including multi-disciplinary work and the experience of organisational processes of decision-making. Adhering to agency protocols and legislative directives seemed to enhance their ability to engage with families. Unlike the post-qualifying cohort, the newly qualified workers did not link decisionmaking with formal supervision, suggesting their decision-making was influenced by other professional perspectives:

'Part of the process is recognising other professionals, bringing different perspectives, accepting others' points of view, backing down, talking to the extended family, bringing the family on board, listening to the voice of the child'.

For the post-qualifying respondents, decision-making was heavily entrenched within organisational governance:

'I was introduced to a workbook - social care governance - through PQ; this was scaringly new and had an impact on me'.

The second general theme arising from the data -impact of learning devolved into two specific themes, namely: (a) the emotional impact of the learning and (b) the instrumental impact of the learning. The first of these concerned, primarily, the heightening of the 'fear factor':

'People are scared witless, paralysed. There is fear amongst senior managers of getting anything wrong'. 
More than that, though, the emotional impact sharpened the worker's sense of what constituted safe practice. Hence, for the newly qualifed social workers, there was a realisation they needed to adhere to agency policy and procedure, and maintain a child-centred awareness at all times. In other words, the instrumentalisation of practice was brought into a much sharper focus. After considering the 'Baby Peter' findings, one respodent said:

'You need to keep on your toes'.

The post-qualifying cohort suggested the teaching often emphasised the negative, emotionally laden aspects of practice to the exclusion of 'what worked':

'On PQ front, it was all the downside that got more emphasis...should have focused on where and what we have done well. Having applied knowledge, I feel nervous managing information on what I am doing'.

'In teaching inquiries, it puts more stress on the worker. You need to look at the full effects. People panic about paperwork; it's the paperwork you worry about'.

Significantly, the post-qualifying group underscored the importance of working within a governance framework and discharging instrumental tasks as defined by organisational protocols including the central need to work in liaison with other disciplines and agencies.

\section{Discussion and Conclusion}

There were a number of limitations in the design of this research. First, a selfcompletion questionnaire, and semi-structured, telephone interview, are not methods of data acquisition that penentrate deeply into the respondents' experience of this emotive area of learning. As such, this research constituted an exploratory review of the topic but one that may, nevertheless, assist in informing more in-depth inquiries - perhaps of a longitudinal or phenomenological nature. There is a well-rehearsed argument that research on social work education, as a distinct field of investigation, requires better and more elaborate methodological designs addressing areas such as behavioural change (Carpenter, 2011). 
Moreover, the study was not able to probe how the learning was developed in practice learning placements or through post-qualifying experience including supervision. In social work, the transfer of formal knowledge to the real world, is a conceptual task involving critical reflection and practice wisdom. The use and adaptation of knowledge will be affected by the managerial and organisational contexts, by limited resources and also the nature of uncertain and complex practice settings. Longitudinal designs may assist in analysing the impact of these situational contingencies and enable more specific questions to be asked.

A critical review of the design might, secondly, pinpoint the absence of hard, objective measures dealing with the impact of learning on professional practice and the outcomes thereof. In this context, the measurement of outcomes is a 'hot topic' in the current literature on the effectiveness of social work education (Burgess \& Carpenter, 2010). What is presented here, instead, are the respondents' subjective views on areas such as decision-making, risk assessment and communication. Hence, the results, overall, might be prone to some degree of bias as encapsulated in the vagaries of memory and student recall. Other factors affecting their judgement could be put down to different experiences of teaching and learning, depending on the courses or modules attended, as well as the nature of their practice learning placements or postqualifying experience. What is more, student perceptions would have been influenced by the extent to which they availed assiduously of the course materials, attended all the lectures and participated fully in interactive learning strategies. Nevertheless, the respondents' collective perceptions in this study were vital to know because, as the sociological adage puts it, 'when people define situations as real, they are real in their consequences'.

These limitations aside, there were a number of significant themes arising from the results. With reference to the primary cross-tabulation between the undergraduate and postgraduate populations, there was an approximate, yet discernable, congruence in their views. Thus, the results indicated that both populations' perspectives roughly aligned in terms of supporting the overall quality of the programmes in which they were enrolled. More specifically, there was a convergence in their attitudes towards the helpfulness of the 
teaching methods (utilised to deliver requisite knowledge). Yet, it was noteworthy that around one in five of the students in both groups said the teaching methods were unhelpful.

The cohorts additionally felt the learning contributed positively to skills development and critical thinking: two areas of major concern in the literature (Deal \& Pittman, 2009). Satisfaction ratings, overall, seemed fairly high on the quality of the teaching. It was concerning to note, though, that only just over half of the undergraduate students said the relevant reports had been covered in the curriculum compared to the more positive responses from the postgraduates. This might be explained by the plethora of inquiries and case reviews, and congested nature of the modern, undergraduate, social work curriculum. Constrained by this tension, it is understandable why some programme providers had difficulty prioritising what to cover in their taught sessions. It must also be said that, while there are certain advantages pertaining to a regionally agreed model curriculum (in terms of standardisation), the drawback is that little flexibility is afforded to the programme providers to adapt their delivery depending on need and the profile of the learning group.

The latter observation might partly explain the apparent piecemeal application of different methods of knowledge dissemination. For example, the majority of the respondents suggested they had only experienced one interactive session. Yet, it must also be recognised that both of the undergraduate courses, in particular, were disseminating learning to significantly large groups of students. This scale of delivery puts inevitable constraints on the range and diversity of teaching methods that can be employed.

Tellingly, only four of the postgraduate students said they experienced a session involving a service user. This represents a notable gap given the increasing emphasis placed on service user involvement in designing, delivering and evaluating social work education (Manthorpe, 2000; Duffy, 2008; Anghel \& Ramon, 2009). However, it must also be recognised that service user involvement in this area is highly complex, emotive and potentially ethically fraught. There is the ever present danger of re- 
traumatising the service user (or students who have experienced past abuse) and incurring potential breaches of confidentiality. More practically, it may be exceptionally difficult to find a service user who is willing and able to take part in the process.

It was further noticeable (and perhaps unsurprising) that the area of child care appeared to get much more coverage than adult services even though both were imbricated in practice, particularly when mental health issues were to the fore. This disproportionate slant might reflect the organisational context where child and family social work is buttressesd by its substantive, statutory remit whereas adult social work often appears less defined in organisational terms. This reason might also partly explain the relative neglect of case reviews and inquiries covering older people.

The respondents also felt that more coverage of regional cases was required suggesting perhaps that major national inquiries dominated the curriculum design. In this context, the parity principle was in evidence showing that policy developments in England and Wales have a continuing resonance (and leverage) in Northern Ireland despite ethno-cultural differences between these nations. The respondents indicated strongly that the curriculum ought to be relevant to their circumstances to assist them in their very demanding roles. Importantly, disseminated knowledge had to connect with everyday experience and have a practical, utilitarian value. Within this frame, knowledge deemed relevant was used to develop holistic practice addressing the needs of family members and also to promote a working together ethos with other professionals.

Yet, the respondents' emphasis on holism, on the one hand, was counterbalanced by the way they underscored governance and proceduralism, on the other. Put differently, obtaining the views of salient members of the family and the professional network was as important as working within a regulatory framework; that is, following the agency's protocols and procedures. This finding resonated with one of Devaney et al's (2013) key learning points about the importance of using prescribed case management systems. It also showed how social workers must balance 'systemic' imperatives (emanating from law and policy) with 'lifeworld' necessities (that 
is, working credibly with families and their surrounding social system) (Hayes and Houston, 2007).

What is more, and of major import, it was most evident that being exposed to teaching about the reviews and inquiries accentuated the 'fear factor'. The analogy of a rabbit caught in the headlights of an oncoming car is apt here. More than that, it was clear that programme providers were not doing enough to address the emotional impact of risk nor the fear of public castigation that followed in the wake of negative outcomes (Rustin, 2005). The possibility of emotional contagion and contamination seemed ever present as students reflected on and discussed the taught sessions - yet was insufficiently processed in the classroom or tutorial. Clearly, if this psychological dimension is not dealt with appropriately, it could lead to a worsening of professional morale, defended behaviour, the possibility of mindless practice and professional dangerousness. Programmes providers and employers may well have a duty to offer a range of supports beyond the classroom including university-based counselling services or work-based, staff support schemes when appropriate.

Linked to this finding, the respondents were clear that programme providers needed to concentrate more on exemplary interventions and illustrate practice that had worked well. This plea endorsed the clarion call in social work for a strengths-based, solution-focused and appreciative perspective (McCashen, 2005) as opposed to mainly centring on a problem-based model of inquiry. Moreover, Munro's (2011) plea for the development of critical thinking, judgement and decision-making in child protection can go some way towards ameliorating the 'fear factor'. Fear steps in when conceptual confidence is at an all time low.

To conclude, this mixed-methods study tackled a salient gap in the literature: how social work students (at qualifying and post-qualifiying levels) made sense of teaching on case reviews and inquiries. Therefore, it attemped to ascertain whether students were helped to take stock of the key messages for practice, analyse them, and effectively transfer this learning to their practice in order to help minimise the risk of repeating the mistakes of the past. Even though contextualised to Northern Ireland, the results should have implications for 
other programme providers in the UK. In this sense, the study acts as a platform for constructing more in-depth designs investigating the nature of social work education in relation to this important topic. While the results indicate that programme providers are taking the area seriously, more development of the curriculum is required covering key gaps in knowledge dissemination and paying attention to the wider implications of this very sensitive topic for students at all stages of their professional development. In particular, programme providers must realise that the transfer of knowledge in this area raises highly charged emotions that need to be acknowledged, processed and mindfully managed. If the psycho-dynamic aspects of learning are not addressed, there is an ever-present danger of exacerbating students' anxieties leaving them, and the families they work with, more vulnerable to negative transactional processes.

\section{Acknowledgement}

This study was funded by the Higher Education Academy. 


\section{References}

Anghel, R. \& Ramon, S. (2009). 'Service User and Carer Involvement in Social Work Education: Lessons from an English Case Study'. European Journal of Social Work, 12(2), 185-99.

Beck, U. (1992). Risk Society: Towards a New Modernity. London: Sage.

Brandon, M., Bailey. \& Belderson, P. (2010). Building on the Learning from the Serious Case Reviews: A Two Year Analysis of Child Protection Database Notifications 2007-2009. London: Department of Education.

Burgess, H. \& Carpenter, J. (2010). (eds.) The Outcomes of Social Work Education. The Higher Education Academy (SWAP): Southampton.

Butler Sloss, E. (1988). Report of the Inquiry into Child Abuse in Cleveland. London: HMSO.

Carpenter, J. (2011). Evaluating Social Work Education: a Review of Outcomes, Measures, Research Designs and Practicalities. Social Work Education, 30, 122140.

Clyde, J. (1992). Report of the Inquiry into the Removal of Children from Orkney. Edinburgh: HMSO.

Committee of Inquiry (1974). Report of the Committee of Inquiry into the Care and Supervision Provided by Local Authorities and Other Agencies in Relation to Maria Colwell. London: HMSO.

Cooper, A. (2005). Surface and Depth in the Victoria Climbié Inquiry Report. Child and Family Social Work, 10(1), 1-10.

Criminal Justice Inspection (2006). The Management of Sex Offenders. Belfast: Criminal Justice Inspection, Northern Ireland.

Deal, K. \& Pittman, J. (2009). Examining Predictors of Social Work Students' Critical Thinking Skills. Advances in Social Work, 10, 87-102.

Devaney, J., Bunting, L. \& Lazenbatt, A. (2013). Translating Learning into Action: An Overview of Learning Arising from Case Management Reviews in 
Northern Ireland 2003-2008. Belfast: Queen's University Belfast, NSPCC and Department of Health, Social Services and Public Safety.

Duffy, J. (2008). Looking Out From the Middle: User Involvement in Health and Social Care in Northern Ireland. London: Social Care Institute for Excellence.

Ferguson, H. (2005). Working with Violence, the Emotions and the PsychoSocial Dynamics of Child Protection: Reflections on the Victoria Climbié Case. Social Work Education, 24(7), 781-795.

Haringey Safeguarding Board (2009). Case Review: Baby Peter. London: Haringey.

Home Office (1999). The Stephen Lawrence Inquiry. London: Home Office.

House of Commons (2003). The Victoria Climbie Inquiry Report. London: The Stationery Office.

House of Commons (2004). The Birchard Inquiry Report. London: HMSO.

Hughes, W. (1986). Report of the Inquiry into Children's Homes and Hostels. Belfast: HMSO.

London Borough of Brent (1985). A Child in Trust: The Report of the Panel of Inquiry into the Circumstances Surrounding the Death of Jasmine Beckford. London: London Borough of Brent.

London Borough of Greenwich (1987). A Child in Mind. London: London Borough of Greenwich.

Mackay, J. (2004). Review of the Findings of Some Homicide Mental Health Inquiries Since 1994. Mental Health Review, 9(2), 28-30.

Manthorpe, J. (2000). Developing Carer's Contributions to Social Work Training. Social Work Education, 19,1, 19-27.

McCashen, W. (2005). The Strengths Approach. Victoria: St. Luke's Innovative Resources.

Munro, E. (2011). The Munro Review of Child Protection - Final Report: A ChildCentred System. London: The Stationery Office. 
Ofsted (2008). Learning Lessons, Taking Action: Ofsted's Evaluations of Serious Case Reviews $1^{\text {st }}$ April 2007 to $31^{\text {st }}$ March 2008. London: Ofsted.

Reder, P. \& Duncan, S. (2004). Making the Most of the Victoria Climbié Inquiry Report. Child Abuse Review, 13(2), 94-114.

Reder, P., Duncan, S. \& Gray, M. (1993). Beyond Blame: Child Abuse Tragedies Revisited. London: Routledge.

Rustin, M. (2005). Conceptual Analysis of Critical Moments in Victoria Climbié's Life. Child and Family Social Work, 10(1), 11-19.

Social Care Institute for Excellence (2009). Safeguarding Adults: Lessons from the Murder of Steven Hoskin. London: Social Care Institute for Excellence.

Stanley, N. \& Manthorpe, J. (2004). The Age of the Inquiry: Learning and Blaming in Health and Social Care. London: Routledge.

Western and Eastern Health and Social Services Boards (2008). Report of the Independent Inquiry Panel, Madeleine and Lauren O'Neill. Derry/Belfast: WHSSB/ EHSSB.

Wrennall, L. (2010). Surveillance and Child Protection: De-Mystifying the Trojan Horse. Surveillance and Society, 7(3/4): 304-324. 